longer roused, his stomach was quiet. Such an explanation, however, does not apply to an account $I$ have received from a very trustworthy medical friend, who told me that a lady patient once told him in sober, serious earnest, that in two out of four pregnancies, she was first made acquainted with her condition, by her husband suffering from morning sickness, herself being quite free therefrom. There was no evidence to account for this curious state of things, and he could only surmise that the affair was accidental-due either to some temporary anxiety, casual marital excess, or some transient cause enfeebling the condition of the stomach.

Hence we see that a consideration of so common a symptom as that we have referred to brings us to that most recondite of all subjects-vital power. It leads us to speculate upon the condition of such power in a woman who is beginning to impart some of her life to a new being. We cannot speculate upon this without turning our thoughts to her partner, and as we do so memory heaps up a vast number of instances, amongst the lower animals, in which the act of generation has been followed at once by the death of the male, as it is subsequently by death in the female. It is true that in the higher animals such occurrences are rare, yet $I$ have met with no less than three cases, in man, where immediate death followed connexion. Once after great loss of blood; another during a transient im. provement in phthisis : in a third the man was weak, from diabetes, and got up from his marriage bed only to return to it to die before evening. But however interesting these speculations may be, it will be unprofitable to carry them farther.

\section{CASE OF EXTRAUTERINE FETATION.}

By Francis Whitweli, Esq., Shrewsbury.

HARRIET MADELEY, an unfortunate, aged 19, admitted into the Atcham Union House on November 13th, 1859, for an injury of the ankle, was seized on the morning of January 26th, 1860 , with partial syncope and severe intermitting pains in the umbilical and hypogastric regions.

On my arrival, she had a pale anxious face; the pulse was scarcely perceptible; the surface of the body was cold; and the abdomen was distended and extremely painful. Stimulants, external heat, and small doses of turpentine, etc., were ordered; but she never rallied, and died on the morning of the 29 th.

AuTOPsy, twenty-four hours after death. The body was well formed, and loaded with fat. On laying open the abdomen, a fotus of about four months, enveloped in its trans. parent membranes, was seen floating in the liquor amnii, and cushioned on the intestines. On tracing the funis downwards, the pelvis was found filled with clots of blood, and the um-

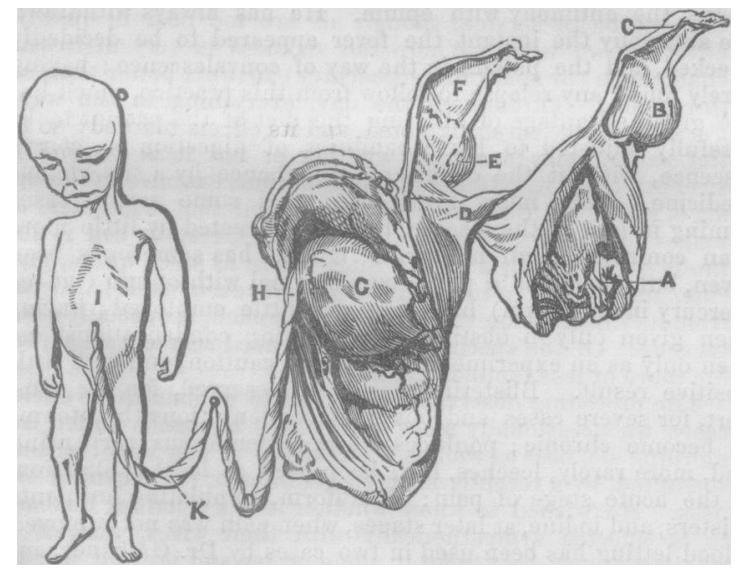

A. Uterus laid open. B. Left Ovary. C. Left Fallopian Tube. D. Right Broad Ligament. F. Right Ovary. F. Right FalloDian Tube. G. Placenta. H. K. Funis. I. Fœtus.
p. Right.

bilical cord terminating in an irregularly shaped placenta, the central portion of which was attached to a fibrous looking mem. brane continuous with the right Fallopian tube, which, on careful examination, clearly demonstrated that the sac originally containing the fœtus, etc., was formed by the gradual expansion of that tube. The posterior surface of the placenta was in places ragged and torn, no doubt indicating the part from which the hæmorrhage had been poured out. The uterus was somewhat enlarged, and presented on its anterior surface and fundus evidence of recent inflammatory action. On being laid open, the interior was found to contain a small quantity of fibrinous looking matter-probably the deciduous membranethe removal of which seemed to carry with it the softened mucous lining. The os was closed with a thick jelly-like substance. The other organs of the body were not examined.

I have since been informed that, during her residence in the Union House, she frequently complained to the other women that " she had something alive in her belly, which moved from side to side".

Had this remark been communicated to me, and a careful examination made, prior to the bursting of the Fallopian sac, how far such a case might have been diagnosed with sufficient accuracy to justify an attempt being made, when the sac gave way, to save the patient by removing the extrauterine fœtation, through an incision in the abdomen, I shall leave to the con. sideration of others.

The woodcut which illustrates this case is from a photo. graph taken by Mr. Groom of Shrewsbury. The pathological specimen is deposited in the museum of the Middlesex Hospital.

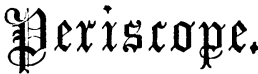

\section{PRACTICE OF MEDICINE AND PATHOLOGY.}

\section{CLINICAL EXPERIENCE OF PNEUMONIA.}

Is the Edinburgh Medical Journal for March 1860, Dr. W. T. GaIrdner, Physician to the Edinburgh Royal Infirmary, has published a paper under the above title, of which the following is an abstract.

While acting as pathologist to the Royal Infirmary from 1848 to 1853 , Dr. Gairdner had become convinced that the tendency to death of many inflammatory diseases, and, in particular, of inflammation of the lungs and pleura, when uncomplicated, was very much overrated. This he inferred from the rare occurrence of deaths due to pneumonia and pleurisy (and also to pericarditis, peritonitis, and acute meningitis), apart from those organic diseases or surgical accidents, which might be said naturally to terminate in one or other of these acute affections. He also inferred, from his experience as pathologist, that this tendency of inflammations to a favourable result was on the increase; or rather, that, in proportion as we were getting rid of the severe forms of epidemic disease (fever, dysentery, scurvy, influenza), which had deteriorated the health of the population previously to 1848 , we were also getting rid of the more severe and unmanageable types of acute inflammation; especially the inflammations of the serous membranes of the chest and abdomen, which he had seen in fearful activity during a few months of the year 1847 , and pneumonia, which, within his own experience as a student, had been a much more fatal disease in hospital practice than it ever became after 1848.

Into the caises of this favourable change, he does not propose at present minutely to inquire, although the inquiry is one of great importance. He believes, however, that the acute inflammations are quite as much, or very nearly as much, within the domain of the sanitary reformer as the more obviously epidemic fevers; and further, that some even of the chronic organic diseases have already yielded, and may be expected still further to yield, to the improved habits, the better clothing, the greater abundance of food, and the diminished destitution of the population generally. Looking back over thirteen years of almost continuous hospital experience, he feels assured that chronic affections of the kidney and liver, and perhaps also of the heart, have diminished in frequency, as causes of death, to a most material extent.

In his paper, Dr. Gairdner proposes to illustrate the actual state of the case as regards pneumonia, or rather pleuropneumonia, by submitting a brief report of the mortality in his wards, in so far as it bears on this disease, during five complete years ending in December 1859. There is only one way of doing this so as not to mislead ; viz., to give an account of all the deaths, whether directly from pneumonia or not, in which decided pneumonia formed part of the disease existing at the time of death. $\mathrm{He}$ enters a caution against using the 